\title{
Drug interactions between antineoplastic and antidepressant agents: analysis of patients seen at an oncology clinic at a general hospital
}

\author{
Interação medicamentosa entre antineoplásicos e antidepressivos: análise de \\ pacientes do ambulatório de oncologia de um hospital geral
}

\author{
Camila de Araújo Reinert, ${ }^{1}$ Marcelo Rodrigues Ribas, ${ }^{2}$ Paulo Roberto Zimmermann ${ }^{3}$
}

\begin{abstract}
Objectives: To determine the prevalence of depressive symptoms among oncology patients and identify simultaneous use of antineoplastic and antidepressant agents.

Methods: This was a cross-sectional study that interviewed 56 oncology patients using two data collection instruments: a questionnaire covering clinical and sociodemographic data and the Beck Depression Inventory-II (BDI-II), for assessment of depressive symptoms. For data analysis, descriptive statistics were used to determine the prevalence of depressive symptoms and the chi-square test was used to evaluate associations between sociodemographic and clinical variables and depressive symptoms.

Results: A $26.7 \%$ (15 patients) prevalence of depression was detected. Just eight of these 15 patients (53.3\%) were receiving treatment for depression. In the sample as a whole, 13 of the patients interviewed $(23.2 \%)$ were taking antidepressants and 11 of these 13 patients (19.6\%) were taking antidepressive and antineoplastic agents simultaneously. A total of five $(8.9 \%$ of the sample) contraindicated drug interactions were detected.

Conclusions: Depressive symptoms are more prevalent among cancer patients than in the general population, but they are generally under-diagnosed and under-treated. Simultaneous use of antidepressant and antineoplastic agents is common and so, in order to reduce the number of harmful adverse effects, possible drug interactions must be identified before antidepressants are prescribed to cancer patients.
\end{abstract}

Keywords: Antidepressive agents, antineoplastic agents, drug interactions, depression, neoplasms.

\section{Resumo}

Objetivos: Verificar a prevalência de sintomas depressivos em pacientes oncológicos e identificar o uso simultâneo de antineoplásicos e antidepressivos.

Métodos: Foi realizado um estudo transversal, no qual 56 pacientes oncológicos foram entrevistados. Foram empregados dois instrumentos: um questionário para a coleta de dados clínicos e sociodemográficos e o Inventário de Depressão de Beck - Segunda Edição (BDI-II) para a avaliação de sintomas depressivos. Para a análise dos dados, foram utilizadas medidas descritivas para determinar a prevalência de sintomas depressivos, o teste de qui-quadrado para avaliar associações entre variáveis sociodemográficas e clínicas e sintomas depressivos.

Resultados: Foi encontrada uma prevalência de depressão de $26,7 \%$ (15 pacientes). Apenas oito desses pacientes (53,3\%) estavam recebendo tratamento para depressão. Considerando a amostra como um todo, estavam fazendo uso de antidepressivos 13 pacientes (23,2\%); destes, 11 faziam uso simultâneo de antidepressivo e antineoplásico (19,6\%). Foram encontradas cinco situações de interações medicamentosas contraindicadas (8,9\%). Conclusão: Sintomas depressivos são mais prevalentes em pacientes oncológicos do que na população em geral, mas geralmente são subdiagnosticados e subtratados. O uso simultâneo de antidepressivos e antineoplásicos é frequente. Sendo assim, para reduzir os efeitos adversos prejudiciais, as possíveis interações medicamentosas devem ser identificadas antes que os antidepressivos sejam prescritos para pacientes oncológicos.

Descritores: Antidepressivos, antineoplásicos, interação de medicamentos, depressão, neoplasias.

\footnotetext{
${ }^{1}$ MD. Board certified in Psychiatry, Pontifícia Universidade Católica do Rio Grande do Sul (PUCRS), Porto Alegre, RS, Brazil. ${ }^{2}$ Medical student, PUCRS, Porto Alegre, RS, Brazil. ${ }^{3}$ Psychiatrist. PhD in Sciences, Graduate Program in Psychiatry, Universidade Federal de São Paulo (UNIFESP), São Paulo, SP, Brazil. Full professor, Department of Psychiatry, PUCRS, Porto Alegre, RS, Brazil.

Financial support: none.

Submitted Jan 26 2015, accepted for publication Mar 31 2015. No conflicts of interest declared concerning the publication of this article.

Suggested citation: Reinert CA, Ribas MR, Zimmermann PR. Drug interactions between antineoplastic and antidepressant agents: analysis of patients seen at an oncology clinic at a general hospital. Trends Psychiatry Psychother. 2015;37(2):87-93. http://dx.doi.org/10.1590/2237-6089-2015-0003
} 


\section{Introduction}

The physiological and emotional changes that patients with cancer go through very often cause psychological suffering and predispose them to psychiatric disorders or exacerbate pre-existing psychiatric conditions. It is already known that psychiatric disorders are more prevalent among oncology patients than in the general population, affecting around $30-40 \%$ of patients with cancer. ${ }^{1}$

The prevalence of depressive symptoms among oncology patients varies depending on type of cancer, disease stage, moment and method of symptom assessment, diagnostic criteria applied and the demographic profile of the population studied. ${ }^{2}$ Prevalence rates of depressive symptoms vary from approximately 10 to around $40 \%$ of patients with cancer. ${ }^{3}$ Prevalence rates are even greater among patients who are taking antineoplastic medications such as interferon-alpha, which is a treatment that is associated with depression in 21 to $58 \%$ of cases. ${ }^{4}$

Psychotropic drugs are often prescribed for patients with cancer, both for treatment of symptoms such as insomnia, pain or nausea and also to treat psychiatric disorders. One study conducted in North America assessing prescription of antidepressants to patients with cancer observed that such drugs are prescribed to one in every seven patients treated in outpatients or clinics. ${ }^{3}$

Many antineoplastic drugs share the same metabolic pathways as psychotropic agents; for example those that undergo transformation by CYP 450 3A4. Coadministration of these antineoplastic agents with antidepressive agents such as fluoxetine, sertraline, paroxetine and fluvoxamine, which are inhibitors of this cytochrome isoform, can reduce the efficacy of the antineoplastic or increase its toxicity. ${ }^{5}$ Additionally, pharmacodynamic interactions can result from synergism or antagonism of the physiological effects of drugs. ${ }^{6}$

When prescribing antidepressants, care should be taken with regard to their pharmacokinetic and pharmacodynamic profiles in order to avoid undesired interactions. For example, the antidepressants escitalopram, citalopram, venlafaxine, mirtazapine and milnacipran are of interest because of their low potential for inhibiting CYP450 and their better safety profiles in oncology patients. ${ }^{5}$ Additionally, it is also of interest to consider whether some of the side effects of these medications may be beneficial to the patient, such as the analgesic and antiemetic effects often observed with mirtazapine. ${ }^{7}$

Patients who take psychotropic and antineoplastic agents concomitantly are exposed to the risk of drug interactions. The narrow therapeutic window and inherent toxicity of many antineoplastic drugs raise serious concerns, since the clinical consequences can be severe. ${ }^{1}$ There are therefore specific precautions that should be taken when prescribing psychotropic agents for oncology patients, such as titrating the dosage to a level appropriate to the physical condition of the patient (generally half dosage for some days). ${ }^{8}$

Additionally, bearing in mind the prevalence of depressive symptoms and the high degree of debilitation that comes with them, it is essential to overcome the very frequent under-diagnosis of depression, with the objective of providing interventions both of a psychosocial and drugbased nature, since both approaches have proven effective for treatment of depression in patients with cancer. ${ }^{9}$

The primary objective of this study was to identify possible drug interactions between antineoplastic and antidepressive agents prescribed to patients seen at the Oncology Clinic at the Hospital São Lucas - Pontifícia Universidade Católica do Rio Grande do Sul (HSL-PUCRS) in Brazil. More specific objectives were as follows: to determine the prevalence of simultaneous antineoplastic and antidepressant agent usage; to determine the prevalence of depressive symptoms among patients seen at the Oncology Clinic; and to trace the clinical, psychiatric and sociodemographic profiles of patients receiving care at the Oncology Clinic.

\section{Method}

\section{Sample}

A cross-sectional study was conducted of 56 oncology patients seen at the Oncology Clinic at HSL-PUCRS. Over a 3-week period, from January to February of 2014, patients seen at the clinic were invited to take part in the study, forming a sample of convenience.

\section{Ethical considerations}

All patients who agreed to take part and signed the free and informed consent form were enrolled on the study. Patients were excluded if they were incapable of reading or understanding the data collection instruments or had mental retardation (according to the authors' clinical observations during the interview) and patients aged less than 18 years at the time of data collection were also excluded. The project was approved by the Research Ethics Committee at the HSL-PUCRS under protocol number 452.960, on 25th October, 2013.

\section{Instruments}

The research instrument employed for data collection was the Beck Depression Inventory-II (BDI-II). 
Additionally, the following data on the patients' sociodemographic profiles were collected by interview and review of medical records: age, marital status, occupation, religion, educational level, habits related to smoking, drinking alcohol and practicing physical activity, other chronic diseases, time since diagnosis, primary disease site, surgery, radiotherapy and chemotherapy, pain and nausea, personal or family history of psychiatric disease, and use of antineoplastic and psychotropic agents. When simultaneous use of antineoplastic and antidepressive agents that is contraindicated by the medical literature was detected, the patient's treating physician was informed.

The BDI-II is considered an excellent method for screening for depression in patients with cancer with a good capacity for generalization and high levels of reliability and validity, when compared with a structured clinical interview conducted by professionals. ${ }^{10}$ The BDIII has also been considered adequate for screening of patients with cancer because of its ease of administration combined with a short duration of administration (approximately 10 minutes) and robust psychometric properties. ${ }^{11}$ A cutoff point of 20 points was chosen, which includes moderate and severe depression. ${ }^{12}$ Patients' treating physicians were informed of a positive screening result for depressive episode if the patient scored more than 20 points on the BDI-II.

\section{Statistics}

The prevalence of depressive symptoms was determined and the sample was characterized using descriptive statistics. The chi-square test was used to assess risk factors associated with depressive symptoms, considering results with a $\mathrm{p}$ value less than 0.05 to be significant. Analyses were conducted using SPSS, version 17.0.

\section{Results}

A total of 14 men and 42 women were interviewed. Patients were aged from 27 to 78 years, with a mean of 56.5 years. The majority of patients were married $(57.1 \%)$, had only completed primary education $(62.5 \%)$, were retired or on sick leave $(64.2 \%)$, did not smoke $(53.5 \%)$, did not drink alcohol (85.7\%) and did not engage in physical activity (58.9\%) (Table 1 ).

With regard to clinical data, $41 \%$ of the patients had been diagnosed with cancer more than 2 years previously and $80.3 \%$ of the sample had been given chemotherapy. The most common sites of neoplasm were the breasts and digestive system. With regard to psychiatric treatment, $69.6 \%$ of the patients had never been treated by a psychiatrist. The majority of patients' perceived their own health to be good (58.9\%) (Table 2).

The prevalence of a positive BDI-II screening result for moderate to severe depressive symptoms among the sample of patients who took part in this study was $26.7 \%$ ( 15 cases). The mean BDI score was 14.7 points and the highest score was 55 points.

Analysis of adjusted residuals showed that patients who considered their own health to be poor or very poor had a stronger association with positive BDI-II screening results $(p=0.009)$ (Table 3$)$.

Patients who reported that their marital status was widowed had a stronger association with positive BDI-II screening results $(p=0.035)$. There were no correlations between depressive symptoms and sex, age or any other clinical or sociodemographic findings (Table 4).

In responding to the sociodemographic questionnaire, 13 patients $(23.2 \%)$ reported that they were currently taking antidepressive agents, but this information was only recorded on three patient records. Eleven patients (19.6\%) were taking antidepressive and antineoplastic agents simultaneously and five cases of contraindicated drug combinations were identified $(8.9 \%)$ (Table 5 ).

Table 1 - Description of sociodemographic data $(n=56)$

\begin{tabular}{|c|c|c|}
\hline & $\mathbf{n}$ & $\%$ \\
\hline Age (mean) & 56.5 & \\
\hline \multicolumn{3}{|l|}{ Marital status } \\
\hline Married or stable relationship & 32 & 57.1 \\
\hline Single & 10 & 17.8 \\
\hline Separated & 8 & 14.2 \\
\hline Widowed & 5 & 8.9 \\
\hline \multicolumn{3}{|l|}{ Educational level } \\
\hline Primary education & 35 & 62.5 \\
\hline Secondary education & 14 & 25 \\
\hline Higher education & 5 & 8.9 \\
\hline \multicolumn{3}{|l|}{ Occupation } \\
\hline Paid employment & 11 & 19.6 \\
\hline Unemployed & 2 & 3.5 \\
\hline Retired or on sick leave & 36 & 64.2 \\
\hline Unpaid employment (student or homemaker) & 5 & 8.9 \\
\hline Other & 2 & 3.5 \\
\hline \multicolumn{3}{|l|}{ Smoking } \\
\hline Yes & 10 & 17.8 \\
\hline No & 30 & 53.5 \\
\hline Reformed smoker & 15 & 26.7 \\
\hline \multicolumn{3}{|l|}{ Alcohol consumption } \\
\hline Daily or almost every day & 0 & 0 \\
\hline Occasionally & 8 & 14.2 \\
\hline None & 48 & 85.7 \\
\hline \multicolumn{3}{|l|}{ Physical activity } \\
\hline Daily or almost every day & 10 & 17.8 \\
\hline Occasionally & 13 & 23.2 \\
\hline None & 33 & 58.9 \\
\hline
\end{tabular}

Trends Psychiatry Psychother. 2015;37(2) - 89 
Table 2 - Description of clinical data $(n=56)$

\begin{tabular}{|c|c|c|}
\hline & $\mathbf{n}$ & $\%$ \\
\hline \multicolumn{3}{|l|}{ Time since diagnosis } \\
\hline Less than 6 months & 11 & 19.6 \\
\hline 7 to 12 months & 11 & 19.6 \\
\hline More than 1 year & 9 & 16 \\
\hline More than 2 years & 23 & 41 \\
\hline Information not provided & 2 & 3.5 \\
\hline \multicolumn{3}{|l|}{ Treatment } \\
\hline Chemotherapy & 45 & 80.3 \\
\hline Radiotherapy & 26 & 46.4 \\
\hline Surgery & 32 & 57.1 \\
\hline Information not provided & 1 & 1.7 \\
\hline \multicolumn{3}{|l|}{ Psychiatric treatment } \\
\hline Currently & 2 & 3.5 \\
\hline In the past & 15 & 26.7 \\
\hline Never & 39 & 69.6 \\
\hline \multicolumn{3}{|l|}{ Perceived general health } \\
\hline Excellent & 5 & 8.9 \\
\hline Very good & 5 & 8.9 \\
\hline Good & 33 & 58.9 \\
\hline Poor & 10 & 17.8 \\
\hline Very poor & 2 & 3.5 \\
\hline \multicolumn{3}{|l|}{ Site of disease } \\
\hline Digestive system & 12 & 21.4 \\
\hline Breast & 14 & 25 \\
\hline Lung & 3 & 5.3 \\
\hline Gynecological & 4 & 7.1 \\
\hline Prostate & 3 & 5.3 \\
\hline Lymphoma & 3 & 5.3 \\
\hline Oropharynx & 5 & 8.9 \\
\hline Melanoma & 5 & 8.9 \\
\hline Others & 6 & 10.7 \\
\hline
\end{tabular}

Table 3 - Perceived health status $x$ positive screening result

\begin{tabular}{lcc}
\hline Health status & $\begin{array}{c}\text { Screening } \\
\text { positive, n (\%) }\end{array}$ & $\begin{array}{c}\text { Screening } \\
\text { negative, n (\%) }\end{array}$ \\
\hline Very good & $1(20)$ & $4(80)$ \\
Good & $1(20)$ & $4(80)$ \\
Moderate & $5(15.2)$ & $28(84.2)$ \\
Poor & $6(60)$ & $4(40)$ \\
Very poor & $2(100)$ & $0(0)$ \\
Total & $15(27.3)$ & $40(72.3)$ \\
\hline
\end{tabular}

Pearson chi-square. Asymp. Sig. (2-sided):0.009.
Table 4 - Marital status $x$ positive screening result

\begin{tabular}{lcc}
\hline Marital status & $\begin{array}{c}\text { Screening } \\
\text { positive, n (\%) }\end{array}$ & $\begin{array}{c}\text { Screening } \\
\text { negative, n (\%) }\end{array}$ \\
\hline Married & $8(25)$ & $24(75)$ \\
Single & $1(10)$ & $9(90)$ \\
Separated & $2(25)$ & $6(75)$ \\
Widowed & $4(80)$ & $1(20)$ \\
Total & $15(27.3)$ & $40(72.7)$ \\
\hline
\end{tabular}

Pearson chi-square. Asymp. Sig. (2-sided):0.035. 
Table 5 - Simultaneous antidepressive and antineoplastic agent use

\begin{tabular}{|c|c|c|c|}
\hline & Antidepressants & Antineoplastic & Drug interaction \\
\hline 1 & Fluoxetine & Oxaliplatin + fluorouracil + leucovorin & $\begin{array}{l}\text { Fluoxetine } \mathrm{x} \text { fluorouracil: risk } \mathrm{D} \text { (consider changing to avoid } \\
\text { increased fluoxetine toxicity)* }\end{array}$ \\
\hline 2 & Imipramine & $\begin{array}{l}\text { Folinic acid/leucovorin + fluorouracil + } \\
\text { irinotecan }\end{array}$ & No interaction reported*+ \\
\hline 3 & Amitriptyline & Imatinib & $\begin{array}{l}\text { Imatinib is a potent inhibitor of CYP2D } 6 \text { and CYP3A4 and } \\
\text { increases serum concentrations of amitriptyline, with increased } \\
\text { risk of toxicity (dose titration recommended) }\end{array}$ \\
\hline 4 & Amitriptyline & Capecitabine & No interaction reported*+ \\
\hline 5 & Venlafaxine & Capecitabine & No interaction reported*+ \\
\hline 6 & Escitalopran & Paclitaxel & No interaction reported*+ \\
\hline 7 & Fluoxetine & Tamoxifen & $\begin{array}{l}\text { Risk D: reduced clinical efficacy of tamoxifen due to reduced } \\
\text { plasma concentration of tamoxifen's active metabolite endoxifen, } \\
\text { caused by CYP2D6 inhibition (dose titration recommended)*+2,6,8 }\end{array}$ \\
\hline 8 & Amitriptyline & Goserelin & No interaction reported*+ \\
\hline 9 & Fluoxetine & Anastrazole & No interaction reported*+ \\
\hline 10 & Paroxetine & $\begin{array}{l}\text { Rituximab }+ \text { cyclophosphamide }+ \\
\text { vincristine+ prednisolone }\end{array}$ & $\begin{array}{l}\text { Paroxetine } \mathrm{x} \text { cyclophosphamide: risk C (paroxetine can } \\
\text { reduce metabolism of cyclophosphamide, increasing its serum } \\
\text { concentrations)*2 }\end{array}$ \\
\hline 11 & Fluoxetine & $\begin{array}{l}\text { Fluororacil + epirubicin + } \\
\text { cyclophosphamide }\end{array}$ & $\begin{array}{l}\text { Fluoxetine } x \text { Fluorouracil: risk D (consider changing to avoid } \\
\text { increased fluoxetine toxicity)* }\end{array}$ \\
\hline
\end{tabular}

Information taken from databases *UpToDate (www.uptodate.com) and ${ }^{+}$MedScape (http://reference.medscape.com/drug-interactionchecker) and from bibliographic references..$^{2,6,8}$

Additionally, eight of the 15 patients with positive BDI-II screening results for depressive symptoms were not being given antidepressive treatment (53.3\%).

\section{Discussion}

The $26.7 \%$ prevalence of positive screening results for depressive symptoms found in the patients investigated in this study is similar to the results of meta-analyses, which have reported rates varying from approximately $10 \%$ to around $40 \%,{ }^{13-15}$ depending on clinical and sociodemographic variables, screening method, cutoff point or diagnosis. There was a significant association between patients' self-perceptions of their own health as poor or very poor and increased prevalence of positive screening results for depressive symptoms and this finding is similar to a previous report showing that the greatest predictor of depressive symptoms among lung cancer patients was functional compromise. ${ }^{16}$ This provides support for the idea that physical complaints and depressive symptoms partially share the same stress pathways and that it is difficult to distinguish cause from effect. ${ }^{15}$ Neurovegetative symptoms observed in depressive patients, for example, may be caused by treatments such as chemotherapy and radiotherapy or by pathological processes inherent to the neoplasm. ${ }^{17}$ The greater prevalence of depressive symptoms that is observed may not be uniquely attributable to psychological stress. Rather, it probably reflects direct activation of physiological processes induced by the disease. The behavioral alterations observed in cancer patients may represent a "disease syndrome," caused by activation of a cytokine inflammatory cascade. ${ }^{17}$ The elevated cytokine levels observed in cancer patients (and also in patients with many other medical conditions) may contribute to inducing depression. ${ }^{18}$

This study also detected a significant association between depressive symptoms and patients who were widows, which is similar to a study of breast cancer patients that found that divorced and widowed women exhibited higher rates of obsessive and depressive findings, and it is easy to imagine that these life-changing events are associated with greater vulnerability and with failures of these patients' support networks, ${ }^{19}$ since social support can ameliorate reactions to stressful events. ${ }^{20}$

Our findings showed that only half of the patients with positive BDI-II screening results were receiving antidepressive treatment. This suggests that patients with depressive disorders may be being underdiagnosed and under-treated. It can be a challenge for physicians specialized in oncology to diagnose a depressive episode, because of lack of training in diagnosis and management of psychosocial disorders. ${ }^{21}$ Many depressive symptoms mimic physiological symptoms that can be caused by both cancer and its 
treatment (fatigue, loss of appetite or weight, sleeping difficulties and loss of memory and concentration, among others) making it more difficult to arrive at the correct diagnosis. ${ }^{22}$ Furthermore, oncologists may encounter difficulties with treatment, since there is no clinical consensus on treating depression in cancer patients. A recent study conducted in Scotland with more than 20 thousand patients reported a $13.1 \%$ prevalence of patients diagnosed with major depressive episodes and found that $73 \%$ of the depressed patients were not receiving any type of antidepressive treatment. ${ }^{23}$

The sociodemographic questionnaire administered in the present study detected 13 patients (23.2\%) who were taking antidepressants, which is a similar pattern to that found by a study conducted at a community cancer treatment center, where $16 \%$ of patients were taking antidepressive medication. ${ }^{21}$ It is important to remember that antidepressant agents are also prescribed to treat other medical conditions, such as the symptoms of menopause and pain. ${ }^{21}$

The fact that patients were taking antidepressant drugs was only recorded on the medical records for three $(23 \%)$ of the 13 patients who reported that they were taking them during the interview conducted to administer the sociodemographic questionnaire. The fact that this information was missing supports the hypotheses that these patients may not be mentioning information related to psychiatric disorders during their consultations or that treating physicians may not be recognizing that the severity of depressive symptoms is sufficient to warrant a need for antidepressant medication. ${ }^{21}$ Oncologists have an increased tendency to underestimate depressive symptoms in more severe patients and screening could prove more effective if cognitive symptoms such as anhedonia, suicidal ideation and despair were recognized. ${ }^{24}$

This study also detected a high number of possible drug interactions, since five $(45.5 \%)$ of the 11 patients who were simultaneously taking antidepressant and antineoplastic agents were taking drugs which, according to a review conducted by the authors of the study, are contraindicated because of interactions. This rate is 2.5 times the number of potential drug interactions (whether clinical or theoretical) detected in a study conducted in Singapore. ${ }^{6}$ Drug interactions can result in reduced drug efficacy and increased adverse effects.

Limitations of this study include the small sample size and the fact that only one instrument was used to screen for depressive symptoms, with no diagnostic confirmation. Notwithstanding, this instrument has been validated for the Brazilian population and has been widely employed to screen for depression in many different studies. ${ }^{25,26}$
Among cancer patients, depression causes increased suffering, lower quality of life and reduced commitment to treatment and can increase the number of days spent in hospital. ${ }^{5,27}$ It has been observed that mortality rates among cancer patients increase by up to $25 \%$ when they have depressive symptoms, ${ }^{13,22}$ possibly due to changes to neuro-immuno-endocrine factors. ${ }^{27}$ Despite the significance of data on related morbidity and mortality, few studies have evaluated depressive symptoms in cancer patients in Brazil, highlighting the need to conduct studies with larger samples that could confirm the findings reported above. Along same lines, it could be helpful to develop protocols providing guidance for clinical conduct of the treatment of depressive episodes in oncology patients, which would be of help to both oncologists and psychiatrists.

\section{Conclusions}

There is a high prevalence of depressive symptoms among cancer patients. Utilization of simple, rapidlyadministered screening instruments such as the BDI-II is important for identification of depressive symptoms in oncological contexts. This study found that just half of the patients whose screening results were positive for depressive symptoms were receiving antidepressant treatment, highlighting the importance of this diagnostic practice.

Furthermore, a large percentage of patients were simultaneously taking medications with a high potential for interaction. This underscores the need to increase the attention that is paid to choosing an antidepressant agent for patients who are taking antineoplastic agents, in order to avoid potential side effects or reductions in the efficacy of both treatments.

\section{References}

1. Meijer A, Roseman M, Milette K, Coyne JC, Stefanek ME, Ziegelstein RC, et al. Depression screening and patients outcomes in cancer: a systematic review. PLoS One. 2011;6:e27181.

2. Miguel C, Albuquerque E. Drug interaction in psychooncology: antidepressants and antineoplastics. Pharmacology. 2011;88:333-9.

3. Okamura M, Azikuzi N, Nakano T, Shimizu K, Ito T, Akechi T, et al. Clinical experience of the use of a pharmacological treatment algorithm for major depressive disorder in patients with advanced cancer. Psychooncology. 2008;17:154-60.

4. Li M, Fitzgerald P, Rodin G. Evidence-based treatment of depression in patients. J Clin Oncol. 2012;30:1187-96.

5. Rodin G, Lloyd N, Katz M, Green E, Mackay JA, Wong RK, et al. The treatment of depression in cancer patients: a systematic review. Support Care Cancer. 2007;15:123-36.

6. Yap KYL, Tay WL, Chui WK, Chan A. Clinically relevant drug interactions between anticancer drug and psychotropic agents. Eur J Cancer Care (Engl). 2011;20:6-32.

7. Bottino SMB, Fráguas R, Gattaz WF. Depressão e câncer. Rev Psiquiatr Clin. 2009;36:109-15.

8. Henry NL, Stearns V, Flockhart DA, Hayes DF, Riba M. Drug 
interactions and pharmacogenomics in the treatment for breast cancer and depression. Am J Psychiatry. 2008;165:1251-5.

9. Schneider S, Moyer A. Depression as a predictor of disease progression and mortality in cancer patients: a meta-analysis. Cancer. 2010;116:3304

10. Saylor MS, Smetana RF. Potential for drug-drug interactions in treating cancer-related nausea and distress. J Oncol Pharm Pract. $2011 ; 17: 403-8$.

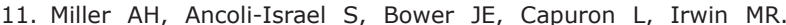
Neuroendocrine-immune mechanisms of behavioral comorbidities in patients with cancer. J Clin Oncol. 2008;26:971-82.

12. Beck AT, Steer RA, Brown GK. Manual for Beck Depression Inventory II. San Antonio: Psychological Corporation; 1996.

13. Mitchell AJ, Chan M, Bhatti $H$, Halton M, Grassi L, Johansen $C$, et al. Prevalence of depression, anxiety, and adjustment disorder in oncological, haematological, and palliative-care settings: a meta-analysis of 94 interview-based studies. Lancet Oncol. 2011;12:160-74.

14. Pinquart $M$, Duberstein PR. Depression and cancer mortality: a meta-analysis. Psychol Med. 2010;40:1797-810.

15. Warmenhoven F, van Rijswijk E, Engels $Y$, Kan C, Prins J, van Well $\mathrm{C}$, et al. The Beck Depression Inventory (BDI-II) and a single screening question as screening tools for depressive disorder in Dutch advanced cancer patients. Support Care Cancer. 2012;20:319-24.

16. Hopwood $\mathrm{P}$, Stephens RJ. Depression in patients with lung cancer: prevalence and risk factors derived from quality-of-life data. J Clin Oncol. 2000;18:893-903.

17. Raison $\mathrm{CL}$, Miller $\mathrm{AH}$. Depression in cancer: new developments regarding diagnosis and treatment. Biol Psychiatry. 2003;54:28394.

18. Pollak $Y$, Yirmiya R. Cytokine-induced changes in mood and behaviour: implications for 'depression due to a general medical condition', immunotherapy and antidepressive treatment. Int J Neuropsychopharmacol. 2002;5:389-99.

19. Fafouti M, Paparrigopoulos T, Zervas $Y$, Rabavilas A, Malamos N, Liappas I, et al. Depression, anxiety and general psychopathology in breast cancer patients: a cross-sectional control study. In Vivo. 2010;24:803-10.
20. Ringdall GI, Ringdal K, Jordhøy MS, Kaasa S. Does social support from family and friends work as a buffer against reactions to stressful life events such as terminal cancer? Palliat Support Care. 2007;5:61-9.

21. Ashbury FD1, Madlensky L, Raich P, Thompson M, Whitney G, et al. Antidepressant prescribing in community cancer care. Support Care Cancer. 2003;11:278-85.

22. Pasquini M, Biondi M, Costantini A, Cairoli F, Ferrarese G, Picardi $A$, et al. Detection and treatment of depressive and anxiety disorders among cancer patients: feasibility and preliminary findings from a liaison service in an oncology division. Depress Anxiety. 2006;23:441-8.

23. Walker $\mathrm{J}$, Hansen $\mathrm{CH}$, Martin $\mathrm{P}$, Symeonides $\mathrm{S}$, Ramessur $\mathrm{R}$, Murray G, et al. Prevalence, associations, and adequacy of treatment of major depression in patients with cancer: a crosssectional analysis of routinely collected clinical data. Lancet Psychiatry. 2014;1:343-50.

24. Passik SD, Dugan W, McDonald MV, Rosenfeld B, Theobald $\mathrm{DE}$, Edgerton $\mathrm{S}$. Oncologists' recognition of depression in their patients with cancer. J Clin Oncol. 1998;4:1594-600.

25. Vodermaier A, Linden W, Siu C. Screening for emotional distress in cancer patients: a systematic review of assessment instruments. J Natl Cancer Inst. 2009;101:1464-88.

26. Hopko DR, Bell JL, Armento ME, Robertson SM, Hunt MK, Wolf NJ, et al. The phenomenology and screening of clinical depression in cancer patients. J Psychosoc Oncol. 2008;26:31-51.

27. Singer S, Das-Munchi J, Brahler E. Prevalence of mental health conditions in cancer patients in acute care - a meta-analysis. Ann Oncol. 2010;21:925-30.

\section{Correspondence:}

Camila de Araújo Reinert

Av. Carlos Gomes 403, sala 602

90480-003 - Porto Alegre, RS - Brazil

E-mail: reinertcamila@gmail.com 